\title{
Poder, língua e a poética do pós-colonialismo
}

\author{
IAIN CHAMBERS \\ Universitá degli Studi di Napoli l'Orientale
}

\begin{abstract}
RESUMO: ESTE BREVE ENSAIO PROCURA IDENTIFICAR ALGUMAS DAS QUESTÕES CRÍTICAS QUE EMERGEM QUANDO UMA LÍNGUA, LITERATURA E CULTURA VIAJAM PARA OUTRO LUGAR E REGRESSAM, TRAZENDO OUTRAS HISTÓRIAS E CULTURAS. A NARRAÇÃO DA NAÇÃO, NOS ESPAÇOS COLONIAIS DA CASA E DO ESTRANGEIRO, É AQUI ATRAVESSADA, INTERROMPIDA, VIRADA DO AVESSO E, EM SEGUIDA, RESSITUADA NA "TRADUÇÃO", INFLUENCIADA POR CORPOS E VOZES NÃO AUTORIZADOS. É PRECISAMENTE A PROVA DESTES PROCESSOS CRIOULIZANTES QUE PROMOVE UMA CONSCIÊNCIA GLOBAL TANTO DE UMA POÉTICA PÓS-COLONIAL EMERGENTE QUANTO DE UMA MODERNIDADE DIFERENCIADA QUE DESENRAIZA QUALQUER REFERÊNCIA À SINGULARIDADE DA CASA/PÁTRIA.
\end{abstract}

ABSTRACT: THIS SHORT ESSAY SEEKS TO PINPOINT SOME OF THE CRITICAL QUESTIONS THAT EMERGE WHEN A LANGUAGE, LITERATURE AND CULTURE TRAVEL ELSEWHERE AND THEN RETURNS BEARING OTHER HISTORIES AND CULTURES. THE NARRATION OF THE NATION, IN THE COLONIAL SPACES OF BOTH HOME AND ABROAD, IS HERE TRAVERSED, INTERRUPTED, TURNED INSIDE-OUT AND THEN RELOCATED IN THE 'TRANSLATION' AFFECTED BY UNAUTHORISED BODIES AND VOICES. IT IS PRECISELY THE EVIDENCE OF SUCH CREOLISING PROCESSES THAT PROMOTES A PLANETARY UNDERSTANDING OF BOTH AN EMERGING POSTCOLONIAL POETICS AND A DIFFERENTIATED MODERNITY THAT UPROOTS ANY APPEAL TO THE SINGULARITY OF HOME.

PALAVRAS-CHAVE: LÍNGUA, LITERATURA, NAÇÃO, MODERNIDADE, POÉTICA PÓSCOLONIAL.

KEYWORDS: LANGUAGE, LITERATURE, NATION, MODERNITY, POSTCOLONIAL POETICS. 
articulação literária é uma forma de violência, do mesmo modo que aquela da formação da nação, à qual está sempre ligada. Desde o início da modernidade que a literatura pertence à nação; para defini-la, são necessárias uma fronteira geográfica e uma cultura dominante que forneçam nome e substância às suas expressões mais diferenciadas.

Lidia Curti

Quem saberá da intertextualidade das nossas cidades fracturadas, excepto nas multilinguas...

Heliodoro Baptista

Será a língua europeia que habita terras longínquas uma máscara branca sobre pele negra? Como uma herança não solicitada do império, será que ela é apenas um fardo linguístico, uma lembrança indesejada da escravatura passada e da subalternidade global presente? Estas línguas (espanhol, inglês, francês e português) que chegaram violentamente d'além-mar levantam estas questões nas Caraíbas, no subcontinente indiano, em toda a África e América Latina. Findo o império e nascidas as novas nações, não foi possível despir a língua imposta, arrancando as camadas da sintaxe dos senhores, e começar de novo. Aquela língua passou a ser a casa para os que antes estavam silenciados e subordinados: os colonizados. Dentro da lógica colonial do poder, a língua em si própria, encaminhada pelos sotaques locais e pela heterogeneidade das influências históricas palpáveis, distorceu-se e transformou-se em crioulo dentro dum mundo infinito da oralidade, sendo uma teimosa testemunha histórica desta herança. Não sendo nem uma propriedade do poder colonial antigo, nem do sujeito pós-colonial, esta língua, simultaneamente global no seu objectivo e local na sua influência, muda, sobrevive, renova-se e persiste.

Nesta perspectiva, hoje é impossível impor uma interpretação unilateral e, desta maneira, "colonizar" a questão. O mundo ex-colonial não pode simplesmente ser tratado como autónomo, assim como não o pode ser o mundo do poder ex-colonial: há uma necessidade urgente e crítica de registar as mudanças nas configurações literárias, culturais e históricas em toda a área das culturas europeias. No caso particular das culturas lusófonas, não se trata apenas da herança do colonialismo português transformado e traduzido nos outros espaços, em Angola, Moçambique, Guiné-Bissau e Cabo Verde; trata-se também da questão de como a língua e a cultura dos "traduzidos", do 
centro metropolitano, são transformadas pelo retorno das outras histórias e narrativas na língua e na literatura que é considerada "própria".

A centralidade do português, agora "desenraizado", nas narrativas múltiplas da pós-colonialidade africana não apresenta nem um reflexo fiel, nem uma mutação monstruosa da sua "origem” europeia. É um fenómeno mais profundo, inesperado e não planeado, que não só "responde" à autoridade antiga, mas também ultrapassa esta dialéctica, já que transmite a sua complexa herança colonial em diversas localizações globais. É definitivamente este ponto que Gayatri Spivak levanta em relação às condições da representação narrativa, sendo elas inseparáveis das do imperialismo (SPIVAK, 1999). Os espaços da modernidade, os próprios interiores das suas cidades, casas, línguas, vidas, são, como menciona Hannah Arendt em The origins of totalitarism, simultaneamente os espaços do colonialismo.

No livro The wretched of the earth, Frantz Fanon tocou na questão do núcleo político e teórico do problema quando afirmou que é o colono que "sabe" que "está a fazer a história" (FANON, 1961). Considerada como uma extensão da história da metrópole, a história criada pelo colonizador não se refere ao país ou ao território que este está a roubar. Portanto, a imobilidade à qual está preso o sujeito colonizado, enquanto objecto da narrativa colonial sobre a modernidade, só pode ser desafiada através da destruição daquela cartografia particular do poder e da historiografia a ela associada. Só através da reescrita dos próprios termos de espaço e de tempo é que os grupos silenciados e subalternos ganham a possibilidade de expressão, partindo das complexidades da história que é múltipla, multilateral, contestada e ainda em construção.

Se a língua - vista como poder colonial e autoridade imperial - viaja, o trânsito não pode escapar às suas inevitáveis transformações nas coordenadas culturais e históricas da língua e da dialéctica locais. A língua recomeça a falar, frequentemente sem autorização do antigo centro metropolitano, e narra mundos e experiências previamente desconhecidas daquela língua. A autoridade de ontem - a mesma língua do poder - é distorcida para revelar uma outra e muitas vezes surpreendente autoria do mundo. É através desta fala, assim como da escrita, de volta ao centro imperial, que a propriedade linguística é questionada. De quem é esta língua? Mesmo se o adjectivo (português, inglês...) revela a origem "europeia", ele não consegue, porém, garantir a resistência à ocupação por outros corpos históricos, ou ao alongamento e 
à costura nos territórios extra-europeus; ou seja, volta a falar e narrar outras versões do mesmo, mas diferente, mundo.

Estamos acostumados a tratar a língua como uma propriedade metafísica que assegura uma sensação palpável de ser e de pertença. A língua é com certeza "nossa", sendo a estabilidade da estrutura transformada numa construção mais móvel quando a língua também se torna casa para os outros. A suposição sobre a relação atemporal entre língua, literatura, cultura, história, geografia e identidade (de facto, ligadas entre si no século dezanove no processo da formação das nações europeias e fundamentalmente relacionadas com a colonização decorrente no resto do planeta) começa a perder a sua validade dado que os próprios termos ficam historicizados, localizados, definidos e, em consequência, são forçados a responder a uma realidade que não tinham autorizado.

A disseminação da língua nacional numa diáspora linguística e literária tem consequências tanto poéticas como políticas. Numa relação assimétrica do poder entre a antiga metrópole e as novas nações pós-coloniais, a língua comum proporciona um uso explícito do poder económico, político e cultural. Falar e escrever português, ou inglês, não é (e nunca foi), neste contexto, uma actividade inocente. Dentro do abrigo do (aparentemente neutro) material linguístico há uma luta contínua pelo sentido, luta que é condicionada pelo tempo e pelo lugar, pela geografia e pela história, pelo poder, em que esta língua chega a narrar diversos, e até contrastantes e conflituosos, factos. Reconhecendo tanto a continuidade como o corte da ferida colonial, o corpus cultural que leva um nome linguístico ("inglês", "francês", "português"...) deixa de ser uma questão unilateral, mas é um campo conquistado, cruzado por várias narrativas, idiolectos e sotaques. A Europa encontra neste lugar a si própria e a sua história, simultaneamente reproduzidas e deslocadas.

Quando a Europa viaja para os outros espaços e volta desviada para uma outra trajectória histórica, desatada, mas não completamente separada, da Lisboametrópole, isso produz também uma narrativa extensa, mas sempre incompleta e obscura, do "periférico" mundo colonial e das suas repercussões complexas. Escrever em português em Angola e Moçambique provoca tanto a disseminação como a dissecação do "português" como herança linguística, literária, cultural e histórica. É nesta defesa da constelação poética e política, em que certa África circula hoje em dia a partir de cada palavra, cada frase da língua imposta, emprestada, apropriada e re-proposta, que se encontra a inscrição do poder. 
Este poder não é meramente um poder de dominação, imposto por uma autoridade nacional ou local, por uma instituição económica, educativa ou política, por uma hierarquia estabelecida de raça e de género; este poder é também um poder de linguagem, qualquer que seja a sua origem, a propor uma potencialidade: não só uma maneira de existir no mundo, mas também uma maneira de começar a existir. É precisamente nesta fronteira que a produção literária mistura o "político" com o poético, traçando os abrigos do tempo e da memória, variados e insuspeitos padrões e caminhos. Isso sugere-nos ler e responder à produção literária (incluindo representações orais e teatrais) não tanto como um testemunho histórico, mas como uma configuração crítica que ultrapassa a sua localização social estabelecida como "arte" ou "divertimento".

Somos sempre ensinados a considerar os textos, as páginas impressas, em particular das formações culturais subalternas, como um espelho social e cultural da realidade (por mais complicada que esta reflexão seja) e, em consequência, como um objecto relativamente estável de estudo e de interesse. No entanto, a língua como literatura, como uma poética transformativa, é em si uma realidade que desperta um imperativo de re-considerar e re-ver os próprios termos do sentido "estético" e ético; de facto, de repensar as próprias condições da "realidade". Como é que "vemos" e "interpretamos" o mundo?

Propondo a figura deleuziana, esta é uma "linha de fuga" que permite que a arte e a literatura pós-coloniais escapem do ciclo perpétuo de representação, repressão e resistência culturais. É uma transformação do notável conceito do "terceiro espaço", introduzido por Bhabha (BHABHA, 1994), num vector dinámico e em constante desenvolvimento, no qual os próprios termos da compreensão herdada são expostos ao questionamento que não tinha sido nem previsto nem aceite. Neste contexto, o literário, o poético e o artístico proporcionam os pontos cardinais do novo compasso crítico: um que permita uma outra navegação na modernidade global, diferenciada, mas comum.

Dentro desta ideia pós-colonial de linguagem e poética, em que as raízes de qualquer um se transformam em rotas, a localização e o enquadramento global estão ligados em novos mapas de proximidades imprevistas. Os antigos lugares de cruel afastamento e irresolúvel desespero, uma vez suscitados pelo tráfico trans-atlântico de escravos (Lisboa-Luanda-Bahia) são hoje em dia transformados numa imediatez de um outro sentido comunitário, baseado na língua e na história (escravatura, colonialismo, imperialismo, nacionalismo). Esta re-escrita 
e re-formulação do passado e do presente é também uma re-escrita das geografias da modernidade e, em particular, das cartografias da cidade pós-colonial, tanto a de Lisboa como a de Luanda ou Maputo. Neste lugar as divisões binárias evidentes, invariavelmente codificadas em raça e racismo, entre o centro metropolitano e a periferia colonial, entre os ricos e os pobres, entre o Primeiro e o Terceiro Mundo, desmoronam nos mapas ainda mais fragmentados e fluídos.

Se estes processos continuam a acontecer "sob o olhar do Ocidente" (Joseph Conrad) - o poder no mundo é profundamente assimétrico na sua distribuição: são os "vencedores" que continuam a escrever a narrativa dominante (BENJAMIN, 1973) - isso já não é simplesmente autorizado pelo Ocidente. Habitar os espaços da cidade pós-colonial e da nação pós-colonial significa habitar uma herança dupla que é simultaneamente local e global. Se os termos são de origem claramente europeia ("literatura", "arte", "estética", "nação"), eles são ao mesmo tempo sujeitos às prácticas transformativas de "desterritorialização" e "reterritorialização” (DELEUZE e GUATTTARI, 1987). Nos seus sotaques locais e cadências flexíveis, o trânsito e a tradução destes termos expõem a promessa e a potencialidade globais que negam os seus lugares de "origem".

O "universalismo" europeu está arrancado da sua casa no hemisfério setentrional e forçado a responder e reagir às suas pretensões globais por se ter tornado uma língua do outro, uma poética do outro. Tudo isso é marcado por uma profunda melancolia: tanto no antigo centro imperial, onde o impacto da perda colonial é em grande parte não reconhecido e insarado, quanto no estado pós-colonial, que vai contestando os fracassos recentes e imaginando uma nação prestes a nascer. É precisamente nesta ferida aberta que a disposição crítica e a poética interrogativa são nutridas e sustentadas.

A própria Europa, junto com os seus cânones literários e estéticos, os seus conceitos políticos e as "liberdades", elaboradas através da subjugação do resto do mundo, está sujeita ao pensamento crítico, dado que as suas línguas viajam agora sem destino pelo mundo. Se em casa o próprio sentido de identidade nacional e de "cânone" literário é incapaz, apesar de toda a defesa institucional e académica, de ficar isolado das tentativas da redefinição contínua, no "estrangeiro" estes conceitos residem em espaços ainda menos estáveis. Isso levanta outra vez a questão: de quem é a língua, a literatura? Visto que a pressuposta homogeneidade de "casa" é agora questionada pela heterogeneidade da modernidade, que não é exclusivamente uma propriedade europeia, 
a própria ideia do "progresso" linear e sequencial também fica desfeita. A difusão através da missão ocidental do colonialismo e da modernidade é um projecto teleológico (e os seus traços religiosos nunca estão longe) que levanta a própria questão: o que compreendemos por "progresso" e "desenvolvimento". Simplificando, o "progresso" para quem, onde, quando e como?

Dentro de uma mistura contemporânea da modernidade global, por mais desigual e injusta que seja a distribuição do poder e das possibilidades, fica impossível traçar uma simples hierarquia de desenvolvimento e progresso. Aqui, a antiga distinção entre tradição e modernidade fica dissolvida num outro espaço. A pressuposta linearidade parte numa série mais fluída de dinâmicas em que a tradição, vista como o lugar de tradução e transformação, se desenvolve e integra na presente realidade dentro da própria modernidade: o curandeiro com um telemóvel.

Tudo isso leva à situação na qual é crucial desatar as narrativas tanto críticas como poéticas do tempo linear. Se o mundo ex-colonial em África está a elaborar a sua herança múltipla dentro do enquadramento inevitavelmente global, ele simultaneamente forma uma parte da resposta contemporânea e não pode estar simplesmente situado num colete de força designado como "subdesenvolvimento" e "Terceiro Mundo", conceptualmente estreito. O desenvolvimento no mundo não europeu, tal como foi durante 500 anos, refere-se às localizações globais e às suas possibilidades.

Um corte tão drástico na perspectiva que salve os sujeitos e as sociedades duma corrida aparentemente impossível para a modernidade - ainda não lá, quase lá, desesperadamente atrás - surge no advento do salto teórico proposto pelo estudioso sardenho Antonio Gramsci e mais recentemente re-proposto pelo crítico palestino Edward Said. Para ambos os intelectuais, a luta política, cultural e histórica não se situa entre a modernidade e a tradição, mas de facto entre a hegemonia e o subalterno. É a partir desta mudança crucial de $180^{\circ}$ nas coordenadas culturais que nasce a reavaliação radical da dinâmica e do sempre inconclusivo sentido de cultura. Reconhecendo as condições da crítica na resistência, no desvio e na mudança, começa a ser possível registar os poderes que buscam ao mesmo tempo configurar e contestar o "sentido comum" da hegemonia.

A primazia da cultura, compreendida não como objecto, mas como uma complexa série de processos e poderes, está plenamente implicada nas interpretações da injustiça que coloca grande parte do mundo numa posição subalterna perante as línguas e os horizontes conceptuais do Ocidente. O próprio excesso 
da linguagem promovida pela sua poética (visual, auditiva e também escrita) provoca a intensidade cultural onde as interpretações escapam aos relatos autorizados. Numa narrativa de tempo e espaço, de passado e presente, o sentido não vem dos factos isolados e acontecimentos pontuais, mas, como insiste Paul Ricoeur (RICOEUR, 1991), surge do ritmo da narração, do complexo, múltiplo e sempre incompleto registo do tempo que nos dota de responsabilidade crítica. Aqui, de baixo, do outro lado surge uma outra cartografia, mais instável, mais sofrida, mais vivida; uma cartografia que, dentro das suas coordenadas heterogéneas, nos atira para um mundo com uma bússola diferente onde "tudo deve ser questionado" (FANON, 1961) e onde, como lembra Gramsci (GRAMSCI, 1975), o resultado da história nunca pode ser conhecido antecipadamente.

Parece-me que as narrativas pós-coloniais, no caso particular de Angola e Moçambique profundamente marcadas pela guerra anticolonial e civil, trespassam este ritmo e território especiais. O espaço pós-colonial é mais abrangente e complexo do que aquele proposto pelas fronteiras físicas e metafísicas do novo Estado-nação. Mesmo se estas narrativas claramente não pertencem ao sujeito europeu, elas questionam este sujeito e deslocam as suas intenções, obrigando a Europa a uma responsabilidade por uma eventual política de escutar o outro. Eu sou forçado a re-pensar o que é a "Europa", "Portugal", e a sua "modernidade", precisamente vistos como produtos do "Terceiro Mundo", como formulou Frantz Fanon (FANON, 1961). Do mesmo modo, e ao mesmo tempo num sentido oposto, Angola e Moçambique já estavam na modernidade muito antes do fim das suas lutas de libertação nacional. As línguas, as modalidades e o resultado destas lutas são em si próprios os sintomas duma modernidade localizada.

Por esta perspectiva, a linguagem crítica, incluída a análise literária e cultural, não pode evitar a contaminação e a crioulização. Não é simplesmente o caso de reconhecer e institucionalmente adaptar as literaturas e a crítica póscoloniais, mas de reconceptualizar "literatura" e "história" como disciplinas, como formas de conhecimento, à luz destas formulações simultaneamente locais e globais. Deste modo, sendo reconhecido ou não, existe um complexo e assimétrico fenómeno comunitário que não é apenas linguístico ou cultural, mas está firmemente seguro pelos laços da gestação global do corpo crioulizado da modernidade. Se a história do Portugal moderno não pode ser separada da África, do Oceano Atlântico, do Oceano Índico e do Oriente, também 
não pode ser aquela de Cabo Verde, da Guiné-Bissau, do Brasil, de Angola e Moçambique. As viagens marítimas, a escravatura, as conquistas comerciais e a administração colonial formam "territórios sobrepostos e histórias entrelaçadas" (SAID, 1993). As ondas culturais à volta do Atlântico, do movimento de Négritude ao modernismo brasileiro e à poética crioulizada das Caraíbas aproximam Paris, Dakar e Luanda, Rio de Janeiro e Maputo, ligando a África, as Américas e a Europa. Como correctamente destacou Patrick Chabal, as narrativas em português, quer sejam escritas em Maputo, na Bahia ou em Lisboa, são escritas e ressoam à luz destas histórias (CHABAL, 1996).

Da escravatura da antiga economia de plantation à biopolítica da guerra pós-colonial e ao estado contemporâneo, encontramos repetidamente o que Achille Mbembe, estudando Fanon, descreve como a força necropolítica da mentalidade colonial. Aqui a lei representa não justiça, mas poder e direito a executar unilateralmente a violência. No entanto, o colonialismo como um projecto global também abriu, inevitavelmente, um tráfico mundial de ambivalência que dissemina, citando outra vez Mbembe, a "densidade de proximidade, de deslocamento, de ruptura até" (MBEMBE, 2008). Aqui, na vida póstuma das crioulizantes economias do imperialismo, ficamos todos estupefactos quando confrontados com uma possibilidade contínua, qualquer que seja o lugar de que falemos, de deslocar a aparentemente "inexausta singularidade do Ocidente" (MBEMBE, 2008).

Apesar das óbvias e enormes desigualdades da riqueza económica, e do poder cultural a ela associado, esta possibilidade indica um mapa definitivamente menos rígido, em que os pressupostos de centro e periferia, cosmopolitismo e localismo começam a flutuar sem apoio nas antigas âncoras. Neste espaço aparece a possibilidade de novos mapas. Um deles é traçado pelas passagens e pelos alcances do português - como uma materialidade linguística, como uma textura cultural e histórica; outro poderia ser aquele proposto na construção do moderno mundo atlântico. Isso incluiria o império português de letras, mas também estenderia as suas questões à(s) América(s) e África, e simultaneamente à Europa.

Tal como existe Europa em África, historicamente de forma mais óbvia através do colonialismo e imperialismo, também existe, embora seja menos reconhecido, África na Europa, disseminada nas suas línguas, literaturas, histórias e culturas. Em ambos os casos, a história colonial e a sua reavaliação pós-colonial propõem uma reconfiguração radical da modernidade, consi- 
derada como uma extensão unilateral exteriorizante da Europa (e Portugal) à escala mundial. Se Angola, Moçambique e o Brasil são claramente nações pós-coloniais no mundo lusófono, Portugal também o é.

Por último, a ruptura pós-colonial volta à "casa" e as disciplinas locais tornam-se contestados sítios de tradução. "História", "antropologia" e "literatura", juntamente com o controlo assumido sobre as fronteiras entre o interior metropolitano e o exterior do além-mar, começam a ser revistas e reconsideradas quando os seus anteriores objectos de estudo - os "nativos", o "indígena" - insistem em ser sujeitos que respondem na mesma língua. "África" ou "Angola" são fundamentalmente uma invenção europeia. A sua subsequente elaboração pós-colonial ocorre neste espaço herdado, expressando um sentido de localidade histórica e cultural imprevisto, dada a proveniência europeia da linguagem histórico-cultural de representação e do Estado-nação associado. Neste desajuste entre o formalismo conceptual e a realidade histórica, a poética questiona e finalmente ultrapassa a sua herança política.

\section{Referências Bibliográficas}

BENJAMIN, Walter. Theses on the Philosophy of History. In BENJAMIN, Walter. Illuminations. Trad. Harry Zohn. London: Collins/Fontana, 1973.

BHABHA, Homi K. The Location of Culture. London-New York: Routledge, 1994.

CHABAL, Patrick, et. al. The Postcolonial Literature of Lusophone Africa. Evanston: Northwesten University Press, 1996.

CUTRI, Lidia. La Voce dell'Altra. Scritture ibride tra femminismo e postcoloniale. Rome: Meltemi, 2006.

DELEUZE, Gilles e GUATTARI, Félix. A Thousand Plateaus: Capitalism and Schirophrenia. Trad. Brian Massumi. Minneapolis: University of Minnesota Press, 1987.

FANON, Frantz. Les damnés de la terre. Paris: Maspero, 1961.

GRAMSCI, Antonio. Quaderni del Carcere. Turin: Einaudi, 1975.

MBEMBE, Achille. What is postcolonial thinking?. Eurozine 12/2008:

www. eurozine. com/articles/2008-01-09-mbembe-en. html.

RICOEUR, Paul. Temps et récit. Paris: Seuil, 1991.

SAID, Edward. Culture and Imperialism. London: Vintage, 1993.

SPIVAK, Gayatri Chakravorty. A Critique of Postcolonial Reason: Towards a History of the Vanishing Present. Cambridge and London: Harvard U. P. , 1999.

Recebido em 04 de Abril e aprovado em 21 de maio de 2010. 